\title{
中国近地表气温直减率及其季节和类型差异
}

\author{
江净超 ${ }^{1}$, 刘军志 ${ }^{2,3^{*}}$, 秦承志 ${ }^{3,4}$, 缪亚敏 ${ }^{2}$, 朱阿兴 ${ }^{2,3}$ \\ (1. 杭州电子科技大学智慧城市研究中心, 杭州 $310012 ; 2$. 南京师范大学虚拟地理环境教育部重点实验室, \\ 南京 $210023 ; 3$. 江苏省地理信息资源开发与利用协同创新中心, 南京 210023; 4. 中国科学院地理 \\ 科学与资源研究所资源与环境信息系统国家重点实验室, 北京 100101)
}

\begin{abstract}
摘 要: 近地表气温直减率是推测近地表气温空间分布的重要参数。中国幅员辽阔, 气候和地形地貌条件复杂, 直 接使用反映对流层平均状况的单一气温直减率 $\left(0.65^{\circ} \mathrm{C} / 100 \mathrm{~m}\right)$ 很难表征中国近地表气温直减率的季节和类型差 异。本文利用中国 839 个国家气象站点 2000-2013 年的近地表气温数据, 分别在国家尺度和综合自然区划尺度上 使用多元回归分析方法计算各个季节的平均气温直减率 $\left(l r_{\mathrm{mena} T}\right)$ 、平均最低气温直减率 $\left(r_{\mathrm{min} T}\right)$ 和平均最高气温直减 率 $\left(l r_{\text {max }}\right)$, 并借助空间插值算法对气温直减率的可靠性进行了验证, 最后分析了其季节和类型的差异。结果表 明: (1)在国家尺度上, 3 种气温直减率均小于 $0.65^{\circ} \mathrm{C} / 100 \mathrm{~m} ; l r_{\text {min } 、} 、 l r_{\text {mant }}$ 和 $l r_{\text {max }}$ 的季节差异分别为 $0.05 、 0.13$ 和 $0.24^{\circ} \mathrm{C} / 100 \mathrm{~m}$, 且一般有夏季最大、冬季最小的季节规律; 春、夏、秋、冬季气温直减率的类型差异分别为 $0.12 、 0.05$ 、 0.11 和 $0.26^{\circ} \mathrm{C} / 100 \mathrm{~m}$, 且有 $l r_{\text {min }}>l r_{\text {mant }}>l r_{\text {max }}$ 的规律。(2)在综合自然区划尺度上, 气温直减率大多低于 $0.65^{\circ} \mathrm{C} / 100 \mathrm{~m}$, 且存在明显的地域差异; 夏季气温直减率一般大于冬季气温直减率, 季节差异大多超过 $0.10^{\circ} \mathrm{C} / 100 \mathrm{~m}$; 气温直减率 类型差异半数区域超过或等于 $0.10^{\circ} \mathrm{C} / 100 \mathrm{~m}$, 在春、夏、秋季, 半数左右的区域 $l r_{\max }>l r_{\min }$, 在冬季, 多数区域的 $l r_{\min }>$ $l r_{\text {max }}, l r_{\text {mean }}$ 一般处于 $l r_{\text {max }}$ 和 $l r_{\text {minT }}$ 之间。
\end{abstract}

关 键 词: 近地表气温直减率; 综合自然区划; 平均气温; 平均最低气温; 平均最高气温; 中国

1 引言

气温直减率是指气温随高度增加而降低的幅 度。在对流层内, 气温直减率平均为 $0.65^{\circ} \mathrm{C} / 100 \mathrm{~m}$, 即平均每上升 $100 \mathrm{~m}$, 气温下降约 $0.65^{\circ} \mathrm{C}$ (中山大学 等, 1978)。近地表气温直减率是指近地表气温随 着地表海拔的升高而降低的幅度, 是推测近地表气 温空间分布的重要参数(山地气候文集编委会, 1984)。近地表气温直减率并不完全等同于对流层 中的气温直减率。此外, 受地理位置、地形地貌和 季节影响, 近地表气温直减率往往存在空间差异和 季节变化(方精云, 1992; Li et al, 2013)。因此,利用
对流层中气温直减率的平均状态 $\left(0.65^{\circ} \mathrm{C} / 100 \mathrm{~m}\right)$ 很 难表征中国近地表气温直减率的时空变化。中国 山区面积占全国陆地总面积的 $2 / 3$ 以上, 且气候、地 形地貌条件复杂多变,近地表气温直减率的时空差 异较大。在全国范围开展近地表气温直减率的定 量化研究, 探究其时空变化模式, 对于中国近地表 气温空间分布信息的准确获取和气候资源的开发 利用具有重要意义。

当前, 已有学者在不同空间范围上对中国的近 地表气温直减率开展了研究, 既有山坡范围的气温 直减率研究(张勇等, 2004; 郑成洋等, 2004; 宋文娟 等, 2009)、山脉范围的气温直减率研究(杨美华,

收稿日期: 2016-04;修订日期: 2016-10。

基金项目: 国家自然科学基金项目(41601423,41601413); 国家重点基础研究发展规划项目(973计划)(2015CB954102); 江苏省 自然科学基金项目(BK20150975) [Foundation: National Natural Science Foundation of China, No.41601423, No.41601413; National Basic Research Program of China (973 Program), No.2015CB954102; Program of Natural Science Research of Jiangsu Province, No.BK20150975]。

作者简介: 江净超(1986-), 男, 河北邢台人,助理研究员, 从事城市地理环境监测和模拟研究, E-mail: jiangjc@hdu.edu.cn。 通讯作者: 刘军志(1984-), 男,山东海阳人,副教授,从事地表过程模拟研究,E-mail: liujunzhi@njnu.edu.cn。 Liu J Z, Qin C Z, et al. 2016. Near-surface air temperature lapse rates and seasonal and type differences in China[J]. Progress in Geography, 35(12): 1538-1548.]. DOI: 10.18306/dlkxjz.2016.12.010 
1981; 刘伟刚等, 2013; 王艳霞等, 2014), 也有全国 范围的气温直减率研究(翁笃鸣等, 1984; 方精云, 1992; 李军等, 2006; Li et al, 2013)。其中, 作为本文 的关注重点, 全国范围的气温直减率研究目前多集 中于年、月尺度平均气温直减率, 鲜有针对平均最 低气温、平均最高气温直减率的研究。而最低、最 高气温不仅是众多地理模型的重要输人 (Hargreaves et al, 1985), 其不对称性变化也已成为全球 变化研究的新热点(Peng et al, 2013)。

本文利用中国国家气象站点的多年近地表气 温数据, 分别在国家尺度和综合自然区划尺度上分 析中国近地表平均气温、平均最低气温和平均最高 气温直减率及其季节和类型差异, 旨在增强对中国 近地表气温直减率的认识, 为气温空间分布信息的 获取与应用提供参数支撑。

\section{2 研究数据}

\section{1 近地表气温数据}

本文所使用的气温数据为中国 839 个国家气象 站点(图 1)2000-2013 年的近地面 $1.5 \mathrm{~m}$ 处逐日平均 气温、最低气温和最高气温(各站点有经度、纬度和 高程等数据)资料,其中 670 个气象站点用于计算气 温直减率, 称之为建模点, 其余 169 个站点用于验 证。各季节、年的平均气温、平均最低气温和平均 最高气温由逐日数据计算得到。其中, 春季包括 3 5 月,夏季包括 6-8 月,秋季包括 9-11月,冬季包括 12-次年 2 月。各季节的平均气温(平均最低气温、 平均最高气温)计算方法为: 将 2000-2013 年各季节 内每天的平均气温(最低气温、最高气温)累计相加, 再除以总天数得到多年各个季节平均气温(平均最

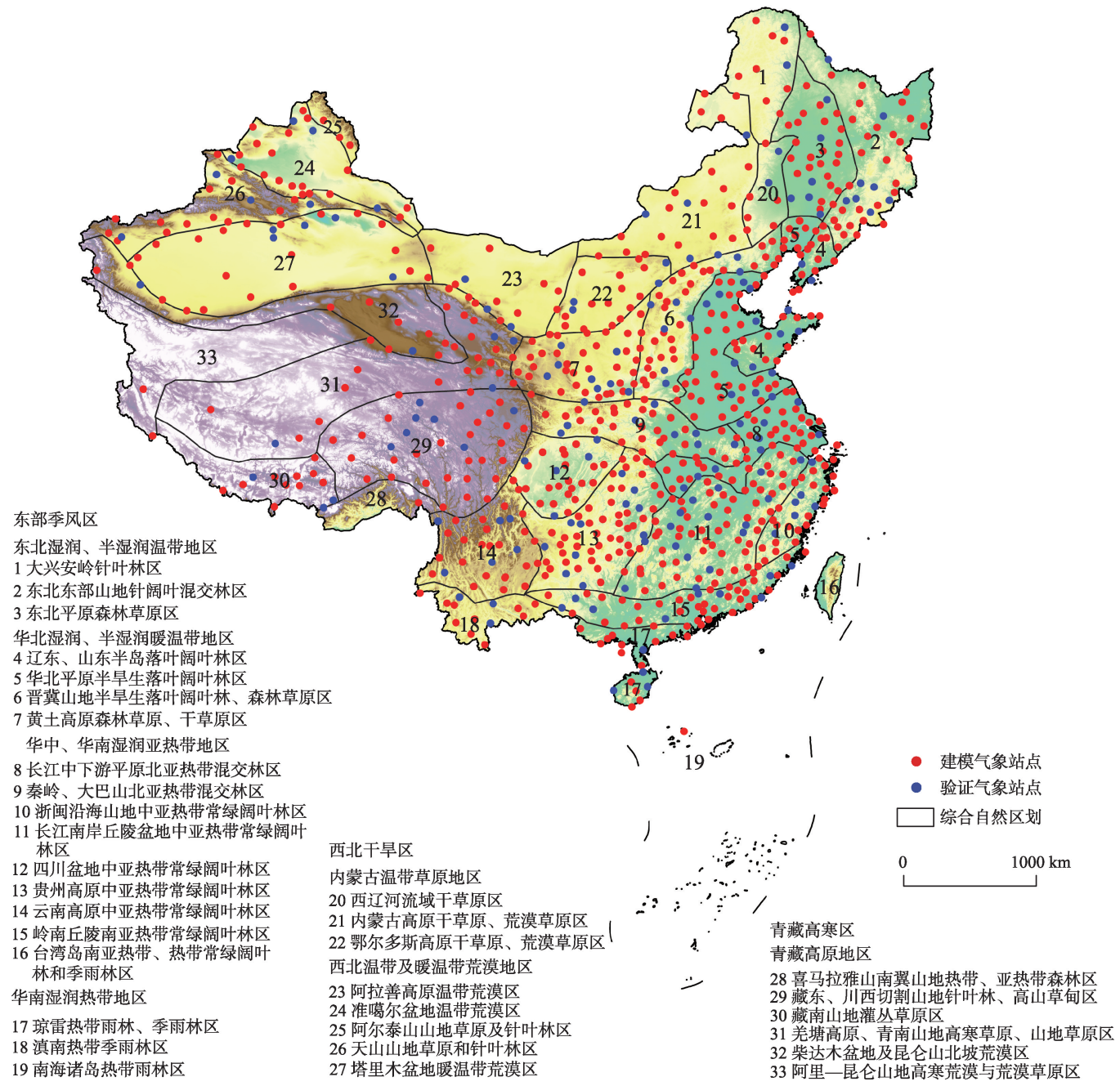

图 1 气象站点分布和综合自然区划图(中国科学院《中国自然地理》编辑委员会, 1985)

Fig.1 Meteorological stations and comprehensive physical geographical regionalization map(Editorial Board of Physical Geography of China, CAS, 1985) 
低气温、平均最高气温)。多年平均气温(平均最低 气温、平均最高气温)计算方法为: 将 2000-2013 年 每天的平均气温(最低气温、最高气温)累计相加, 再 除以总天数得到多年平均气温 (平均最低气温、平 均最高气温)。上述各类型气温将参与气温直减率 计算。

\section{2 综合自然区划数据}

气温直减率存在明显的空间分异现象, 除在国 家尺度计算整体气温直减率外, 还需要划分合理的 子区计算不同区域的气温直减率。考虑到综合自 然区划能体现区域内气候、地形地貌、植被等综合 自然条件的一致性, 本文选择综合自然区划作为子 区划分的依据。中国综合自然区划方案较多, 其中 在《中国自然地理总论》中, 中国综合自然地理区划 (又称为 “赵松乔区划方案”) 明确划出了东部季风 区、西北干旱区、青藏高寒区三大自然区,且在子区 划分中合理体现了温度带和地貌的差异, 干湿状况 也得到体现(中国科学院《中国自然地理》编辑委员 会, 1985)。故本文选择赵松乔区划方案中给出的 33 个分区(图 1)进行中国气温直减率研究。

\section{3 研究方法}

\section{1 气温直减率计算}

气温直减率的计算一般采用线性回归法, 在小 尺度多采用仅考虑高程变量的一元一次回归法求 解(Rolland, 2003; Harlow et al, 2004), 而使用气象站 点的气温资料在大、中尺度计算气温直减率时, 由 于站点间距离一般较远, 还需考虑经度(海陆位置)、 纬度带来的影响(Fang et al, 1988; Li et al, 2013)。 为减少经度、纬度的影响, 本文采用多元一次回归 法, 建立站点气温与经度、纬度和高程的线性函数 关系 (张洪亮等, 2002; 潘耀忠等, 2004; Li et al, 2013):

$$
T=a L o n+b L a t-l r E l e+c
$$

式中: $T$ 为站点气温; Lon、Lat、Ele 分别代表气象站 点的经度、纬度和高程; 待拟合回归系数 $a 、 b 、 l r$ 分 别表示了气温随经度、纬度和高程的变化程度, $l r$ 即 为气温直减率; $c$ 为截距。根据站点多年 (多年季节) 的平均气温、平均最低气温、平均最高气温, 计算出 的 $l r_{\text {mean }} 、 l r_{\text {minT }} 、 l r_{\text {max }}$ 分别为多年(多年季节)平均气 温、平均最低气温、平均最高气温的直减率, 参考 $\mathrm{Li}$ 等(2013)有关气温直减率的表述, 下文统一简称年
(季节)平均气温、年(季节)平均最低气温、年(季节) 平均最高气温直减率。

分别在国家尺度和综合自然区划各分区计算 不同季节气温直减率: 将 670 个建模站点的气温资 料同时代人式(1), 得到国家尺度上的气温直减率; 将落人各个综合自然区划分区内的建模站点的气 温资料分别代人式(1), 得到区划尺度上的气温直 减率。

\section{2 气温直减率可靠性验证}

不同于气温、降雨等气象要素, 气温直减率难 以通过监测设备直接获取。本文通过对比传统空 间插值算法与考虑气温直减率的同一空间插值算 法的气温插值精度, 来验证气温直减率的可靠性。

(1) 利用反距离加权法的气温插值精度评价

本文使用空间插值中常用的反距离加权法对 气温数据进行空间插值, 并使用独立验证的方式评 价插值精度: (1) 利用建模站点处的气温值, 通过反 距离加权法得到验证站点处的气温估算值; (2)计算 验证站点观测值与估计值之间的均方根误差 $R M S E-I D W$, 用于评价空间插值算法的精度。

(2) 考虑气温直减率的反距离加权法气温插值 精度评价

(1)根据气温直减率和建模站点高程计算得到 每个建模站点的虚拟“海平面”气温, 详见式(2)。利 用建模站点处的“海平面”气温值, 通过反距离加权 法得到验证站点处的“海平面”气温估算值, 然后根 据气温直减率和高程将每个验证站点处的“海平 面”估算值统一修正回原始高程, 详见式(3), 得到最 终的气温估计值; 2计算验证站点观测值与估计值 之间的均方根误差 RMSE-DEM, 用于评价考虑气温 直减率的气温插值精度。

$$
T_{0}=T_{\text {Ele }}+\text { lrEle }
$$

式中: $T_{0}$ 为站点的虚拟“海平面”气温值; $T_{E l}$ 为站点 原始高程气温观测值; Ele、 $l r$ 含义同式(1)。

$$
\hat{T}_{E l e}=\hat{T}_{0}-\text { lrEle }
$$

式中: $\hat{T}_{E l e}$ 为站点原始高程气温估算值; $\hat{T}_{0}$ 为站点 “海平面”气温估算值。

对比上述 2 种插值方式的精度差异: 若考虑气 温直减率的空间插值算法所估算气温插值精度更 高, 则表明气温直减率用于气温插值是可靠的; 否 则表明气温直减率无法提高气温插值的精度。在 国家尺度, 所有站点气温修正使用统一气温直减 率; 而在区划尺度, 每个分区内站点气温修正使用 
各自的气温直减率。分别验证整个国家和各个分 区范围内气温直减率的有效性。

\section{3 气温直减率季节和类型差异计算}

为刻画气温直减率的季节差异, 用四季气温直 减率中的最大值减去最小值得到其季节差异, 分别 在国家尺度和区划尺度计算平均最低气温、平均气 温和平均最高气温的直减率季节差异。为刻画不 同类型气温直减率的差异, 用平均最低气温、平均 气温、平均最高气温直减率中的最大值减去最小 值, 得到类型差异, 分别在国家尺度和区划尺度计 算各个季节的气温直减率类型差异。

\section{4 结果与分析}

\section{1 国家尺度上气温直减率及其季节和类型差异}

\subsection{1 气温直减率数值概况}

基于式(1)分别计算了 2000-2013 年国家尺度上 各季节、年的平均最低气温、平均气温和平均最高 气温的直减率(表 1$)$ 。从表 1 可以看出, 在国家尺度 上, 不同季节和不同气温类型的气温直减率均小于 $0.65^{\circ} \mathrm{C} / 100 \mathrm{~m}$, 取值在 $0.19 \sim 0.50^{\circ} \mathrm{C} / 100 \mathrm{~m}$ 。其中, 冬 季的平均最高气温直减率最小, 为 $0.19^{\circ} \mathrm{C} / 100 \mathrm{~m}$; 春 季的平均最低气温直减率最大, 为 $0.50^{\circ} \mathrm{C} / 100 \mathrm{~m}$; 且 式(1)及气温直减率均通过了显著性检验。

\subsection{2 气温直减率可靠性验证}

分别计算基于反距离加权法的气温插值均方 根误差 $(R M S E-I D W)$ 和考虑气温直减率的反距离加 权法的气温插值均方根误差 (RMSE-DEM)(表 2)。 在国家尺度上考虑气温直减率可以有效降低气温 插值算法的均方根误差。从提高各类型气温估算 精度的角度, 本文气温直减率的可靠性得到了验 证。整体来看,考虑春、夏、秋和年的气温直减率可

表 1 国家尺度的平均气温、平均最低气温和 平均最高气温直减率 $/\left({ }^{\circ} \mathrm{C} / \mathbf{1 0 0} \mathrm{m}\right)$

Tab.1 Lapse rates of mean, mean minimum, and mean maximum air temperature at the national scale $/\left({ }^{\circ} \mathrm{C} / 100 \mathrm{~m}\right)$

\begin{tabular}{cccc}
\hline 季节/年 & 平均气温 & 平均最低气温 & 平均最高气温 \\
\hline 春 & $\square 0.44^{* * * *}$ & $\square 0.50^{* * * *}$ & $\square 0.38^{* * * *}$ \\
夏 & $\square 0.46^{* * * *}$ & $\square 0.48^{* * * *}$ & $\square 0.43^{* * * *}$ \\
秋 & $\square 0.44^{* * * *}$ & $\square 0.48^{* * * *}$ & $\square 0.37^{* * * *}$ \\
冬 & $\square 0.33^{* * * *}$ & $\square 0.45^{* * * *}$ & $\square 0.19^{* * * *}$ \\
年 & $\square 0.42^{* * * *}$ & $\square 0.48^{* * * *}$ & $\square 0.34^{* * * *}$ \\
\hline
\end{tabular}

注: $\square$ 表示回归方程通过了显著性检验, $P<0.001 ; \cdots$ 表示气温直 减率通过了显著性检验, $P<0.001$ 。
以大幅度提高气温插值精度, 而由于冬季气温直减 率数值较小, 相对其他季节, 提高气温插值精度的 作用有所减弱。

\subsection{3 气温直减率的季节和类型差异}

在国家尺度上, 中国气温直减率始终表现为 $l r_{\min T}>l r_{\text {meanT }}>l r_{\text {maxt }}$ 的趋势。气温直减率呈现出明显 的季节变化,除 $l r_{\text {min }}$ 在春季达到最高值外,均呈现 夏季最大、冬季最小的特征, 这主要是因为冬季冷 空气侵袭对海拔低处气温的拉低作用较海拔高处 更为剧烈的缘故(张家诚等, 1985)。

$l r_{\text {min } ~} 、 l r_{\text {meanT }} 、 l r_{\text {max }}$ 季节差异分别为 $0.05 、 0.13$ 、 $0.24^{\circ} \mathrm{C} / 100 \mathrm{~m}$, 表明 $l r_{\max }$ 季节性变化最为明显, $l r_{\text {mean }}$ 次之, $l r_{\min }$ 最小; 春、夏、秋、冬季气温直减率的类型 差异分别为 $0.12 、 0.05 、 0.11$ 和 $0.26^{\circ} \mathrm{C} / 100 \mathrm{~m}$, 表明在 夏季 $l r_{\text {min }} 、 l r_{\text {mean } 、} 、 l r_{\max }$ 的差异最小, 而在冬季 3 种类 型气温的直减率差异最大。

\section{2 区划尺度上气温直减率及其季节和类型差异}

\subsection{1 气温直减率数值概况}

基于式(1),分别计算了 2000-2013 年各个季节 平均气温、平均最低气温和平均最高气温直减率 (表 3-5)。需要说明的是, 区域 16(台湾省)、区域 19 (南海诸岛)、区域25(阿尔泰山)、区域 28(喜马拉雅 山南翼)和区域 33(阿里昆仑山)由于站点数据缺失 或过少, 导致无法使用式(1)求取气温直减率。在区 划尺度上, 除个别情况外, 式(1)及气温直减率绝大 多数都通过了显著性检验。

除少数区域和季节, $l r_{\min \mathrm{T}} 、 l r_{\operatorname{mean} \mathrm{T}} 、 l r_{\max }$ 整体呈很 强的显著性。然而在冬季, 气温直减率在个别区域 的显著性较差, 甚至出现逆温现象, 而在其他季节 则很少出现这一现象, 这与冬季冷空气人侵使低海 拔处气温降低, 从而导致气温随高程的变化不明显 有关。与国家尺度类似,除在夏季半数(14个)区域 的平均最高气温直减率高于或等于 $0.65^{\circ} \mathrm{C} / 100 \mathrm{~m}$ 外, 其他情况下大多数(18 25个)区域的气温直减 率低于 $0.65^{\circ} \mathrm{C} / 100 \mathrm{~m}$ 。此外, 中国气温直减率存在 很大的地域差异(图 2), 就年平均气温直减率而言, 区域 5 (华北平原)的气温直减率为 $1.03^{\circ} \mathrm{C} / 100 \mathrm{~m}$, 而 区域 17 (琼雷区) 的气温直减率为 $0.22^{\circ} \mathrm{C} / 100 \mathrm{~m}$; 就 年平均最低气温直减率而言, 区域 5 (华北平原)的气 温直减率为 $1.66^{\circ} \mathrm{C} / 100 \mathrm{~m}$, 而区域 22 (鄂尔多斯高 原) 的气温直减率为 $0.27^{\circ} \mathrm{C} / 100 \mathrm{~m}$; 就年平均最高 气温直减率而言, 区域 21(内蒙古高原)的气温直减 率为 $0.83^{\circ} \mathrm{C} / 100 \mathrm{~m}$, 区域 17 (琼雷区) 的气温直减率 
表 2 国家尺度的不同气温插值方法的均方根误差 $/{ }^{\circ} \mathrm{C}$

Tab.2 RMSEs at the national scale by two different methods $/{ }^{\circ} \mathrm{C}$

\begin{tabular}{|c|c|c|c|c|c|c|}
\hline \multirow{2}{*}{ 季节/年 } & \multicolumn{2}{|c|}{ 平均气温 } & \multicolumn{2}{|c|}{ 平均最低气温 } & \multicolumn{2}{|c|}{ 平均最高气温 } \\
\hline & $R M S E-I D W$ & RMSE-DEM & RMSE-IDW & RMSE-DEM & $R M S E-I D W$ & RMSE-DEM \\
\hline 春 & 3.14 & 1.59 & 3.19 & 1.66 & 3.23 & 1.89 \\
\hline 夏 & 2.92 & 1.10 & 2.93 & 1.16 & 3.04 & 1.43 \\
\hline 秋 & 2.93 & 1.49 & 3.14 & 1.77 & 2.86 & 1.57 \\
\hline 冬 & 3.37 & 2.50 & 3.80 & 2.70 & 3.11 & 2.59 \\
\hline 年 & 2.99 & 1.55 & 3.19 & 1.74 & 2.93 & 1.72 \\
\hline
\end{tabular}

表 3 区划尺度的平均气温直减率/ $\left({ }^{\circ} \mathrm{C} / \mathbf{1 0 0} \mathrm{m}\right)$

Tab.3 Lapse rates of mean air temperature at the regional scale $/\left({ }^{\circ} \mathrm{C} / 100 \mathrm{~m}\right)$

\begin{tabular}{|c|c|c|c|c|c|c|}
\hline 大区 & 区域 ID & 春 & 夏 & 秋 & 冬 & 年 \\
\hline \multirow{17}{*}{ 东部季风区 } & 1 & $\bigcirc 0.65^{*}$ & $\times 0.83^{*}$ & $\bigcirc 0.59^{\times}$ & $\times-0.15^{\times}$ & $\times 0.48^{\times}$ \\
\hline & 2 & $\square 0.56^{* * *}$ & $\square 0.58^{* * *}$ & $\square 0.59^{* * *}$ & $\square 0.51^{* * * *}$ & $\square 0.56^{* * * *}$ \\
\hline & 3 & $\square 0.74^{* * *}$ & $\square 0.91^{* * *}$ & $\square 0.73^{* * *}$ & $\square 0.15^{\times}$ & $\square 0.63^{* * *}$ \\
\hline & 4 & $\square 0.61^{* * *}$ & $\square 0.62^{* * *}$ & $\square 0.58^{* * *}$ & $\square 0.51^{* * *}$ & $\square 0.58^{* * * *}$ \\
\hline & 5 & $\square 0.62^{*}$ & $\square 0.58^{* *}$ & $\square 1.27^{* * *}$ & $\square 1.66^{* * * *}$ & $\square 1.03^{* * * *}$ \\
\hline & 6 & $\square 0.54^{* * *}$ & $\square 0.57^{* * *}$ & $\square 0.49^{* * * *}$ & $\square 0.49^{* * * *}$ & $\square 0.52^{* * * *}$ \\
\hline & 7 & $\square 0.56^{* * *}$ & $\square 0.62^{* * *}$ & $\square 0.48^{* * * *}$ & $\square 0.36^{* * *}$ & $\square 0.51^{* * * *}$ \\
\hline & 8 & $\square 0.45^{* * *}$ & $\square 0.58^{* * *}$ & $\square 0.50^{* * *}$ & $\square 0.40^{* * * *}$ & $\square 0.48^{* * * *}$ \\
\hline & 9 & $\square 0.50^{* * * *}$ & $\square 0.52^{\ldots * *}$ & $\square 0.42^{* * * *}$ & $\square 0.42^{* * * *}$ & $\square 0.46^{* * *}$ \\
\hline & 10 & $\square 0.46^{* * *}$ & $\square 0.59^{* * *}$ & $\square 0.57^{* * * *}$ & $\square 0.40^{* * *}$ & $\square 0.50^{* * * *}$ \\
\hline & 11 & $\square 0.50^{* * * *}$ & $\square 0.62^{* * *}$ & $\square 0.53^{* * *}$ & $\square 0.40^{* * * *}$ & $\square 0.51^{* * * *}$ \\
\hline & 12 & $\square 0.55^{* * *}$ & $\square 0.56^{* * *}$ & $\square 0.53^{* * *}$ & $\square 0.57^{* * *}$ & $\square 0.55^{* * *}$ \\
\hline & 13 & $\square 0.48^{* * *}$ & $\square 0.55^{* * *}$ & $\square 0.53^{* * * *}$ & $\square 0.50^{* * * *}$ & $\square 0.52^{* * * *}$ \\
\hline & 14 & $\square 0.56^{* * *}$ & $\square 0.51^{* * *}$ & $\square 0.49^{* * * *}$ & $\square 0.47^{* * *}$ & $\square 0.51^{* * *}$ \\
\hline & 15 & $\square 0.23^{* * *}$ & $\square 0.48^{* * *}$ & $\square 0.42^{* * *}$ & $\square 0.17^{*}$ & $\square 0.32^{* * *}$ \\
\hline & 17 & $\square 0.11^{\times}$ & $\bigcirc 0.36^{* *}$ & $\triangle 0.35^{*}$ & $\square 0.07^{\times}$ & $\square 0.22^{\times}$ \\
\hline & 18 & $\triangle 0.39^{* * *}$ & $\square 0.50^{* * * *}$ & $\square 0.50^{* * * *}$ & $\triangle 0.36^{*}$ & $\square 0.44^{* * *}$ \\
\hline \multirow{7}{*}{ 西北干旱区 } & 20 & $\bigcirc 0.68^{\times}$ & $\times 1.02^{\times}$ & $\bigcirc 0.67^{\times}$ & $\triangle 0.25^{\times}$ & $\bigcirc 0.66^{\times}$ \\
\hline & 21 & $\square 0.81^{* * *}$ & $\square 0.77^{* * *}$ & $\square 0.72^{* * *}$ & $\square 0.89^{* * * *}$ & $\square 0.80^{* * * *}$ \\
\hline & 22 & $\square 0.63^{* * * *}$ & $\square 0.52^{\ldots * *}$ & $\square 0.46^{* *}$ & $\square 0.43^{*}$ & $\square 0.51^{* * * *}$ \\
\hline & 23 & $\triangle 0.77^{* *}$ & $\triangle 0.79^{* *}$ & $\bigcirc 0.60^{* *}$ & $\bigcirc 0.38^{*}$ & $\bigcirc 0.64^{* * *}$ \\
\hline & 24 & $\square 0.53^{* * *}$ & $\square 0.63^{* * *}$ & $\square 0.41^{* * * *}$ & $\times-0.20^{\times}$ & $\triangle 0.34^{* *}$ \\
\hline & 26 & $\square 0.71^{* * *}$ & $\square 0.72^{* * *}$ & $\square 0.56^{* * *}$ & $\bigcirc 0.25^{*}$ & $\square 0.56^{* * * *}$ \\
\hline & 27 & $\square 0.68^{* * *}$ & $\square 0.74^{* * *}$ & $\square 0.45^{* * *}$ & $\square 0.32^{*}$ & $\square 0.55^{* * * *}$ \\
\hline \multirow{4}{*}{ 青藏高寒区 } & 29 & $\square 0.63^{* * * *}$ & $\square 0.53^{* * *}$ & $\square 0.58^{* * * *}$ & $\square 0.66^{* * *}$ & $\square 0.60^{* * * *}$ \\
\hline & 30 & $\bigcirc 0.85^{* *}$ & $\bigcirc 0.69^{*}$ & $\bigcirc 0.76^{* *}$ & $\bigcirc 0.81^{* *}$ & $\bigcirc 0.78^{* *}$ \\
\hline & 31 & $\square 0.64^{* * *}$ & $\square 0.66^{* * *}$ & $\square 0.56^{* * *}$ & $\square 0.47^{* * *}$ & $\square 0.58^{* * * *}$ \\
\hline & 32 & $\square 0.55^{* * *}$ & $\square 0.53^{* * *}$ & $\square 0.40^{* * * * *}$ & $\triangle 0.36^{* *}$ & $\square 0.46^{* * * *}$ \\
\hline
\end{tabular}

注: 回归方程显著性检验: $\bigcirc 、 \triangle 、 \square 、 \times$ 分别代表 $P<0.05 、 P<0.01 、 P<0.001 、 P>0.05$; 气温直减率显著性检验: * **、***、分别表示 $P<0.05$ 、 $P<0.01 、 P<0.001 、 P>0.05$; 负值代表出现逆温; 区域 ID 同图 1,下同。

为 $-0.10^{\circ} \mathrm{C} / 100 \mathrm{~m}$ 。

4.2.2 气温直减率可靠性验证

分别计算 $R M S E-I D W$ 和 $R M S E-D E M$ (表略)。 结果表明: 整体而言, $R M S E-D E M<R M S E-I D W$, 说
明在区划尺度考虑气温直减率可有效降低气温插 值的误差, 气温直减率的可靠性得到了验证。然 而,在个别情况下,例如区域5(华北平原)和区域 17 (琼雷区)的平均最高气温插值在考虑气温直减率影 
表 4 区划尺度的平均最低气温直减率/ $\left({ }^{\circ} \mathrm{C} / \mathbf{1 0 0} \mathrm{m}\right)$

Tab.4 Lapse rates of mean minimum air temperature at the regional scale $/\left({ }^{\circ} \mathrm{C} / 100 \mathrm{~m}\right)$

\begin{tabular}{|c|c|c|c|c|c|c|}
\hline 大区 & 区域ID & 春 & 夏 & 秋 & 冬 & 年 \\
\hline \multirow{17}{*}{ 东部季风区 } & 1 & $\times 0.77^{\times}$ & $\times 0.92^{\times}$ & $\times 0.66^{\times}$ & $\times-0.17^{\times}$ & $\times 0.55^{\times}$ \\
\hline & 2 & $\square 0.70^{* * * *}$ & $\square 0.78^{* * *}$ & $\square 0.73^{* * *}$ & $\square 0.71^{* *}$ & $\square 0.73^{* * *}$ \\
\hline & 3 & $\square 0.69^{*}$ & $\square 0.97^{* * *}$ & $\square 0.85^{\circ}$ & $\square 0.12^{\times}$ & $\square 0.66^{\times}$ \\
\hline & 4 & $\square 0.51^{* * * *}$ & $\square 0.54^{* * *}$ & $\square 0.47^{* *}$ & $\square 0.45^{* *}$ & $\square 0.49^{* * *}$ \\
\hline & 5 & $\square 1.26^{* * *}$ & $\square 1.10^{* * * *}$ & $\square 1.96^{* * *}$ & $\square 2.33^{* * * *}$ & $\square 1.66^{* * *}$ \\
\hline & 6 & $\square 0.54^{* * * *}$ & $\square 0.59^{* * * *}$ & $\square 0.52^{* * * *}$ & $\square 0.55^{* * *}$ & $\square 0.55^{* * *}$ \\
\hline & 7 & $\square 0.44^{* * * *}$ & $\square 0.52^{* * * *}$ & $\square 0.40^{* * * *}$ & $\square 0.30^{* * *}$ & $\square 0.41^{* * * *}$ \\
\hline & 8 & $\square 0.44^{* * *}$ & $\square 0.52^{* * *}$ & $\square 0.47^{* * * *}$ & $\square 0.43^{* * *}$ & $\square 0.47^{* * *}$ \\
\hline & 9 & $\square 0.53^{* * * *}$ & $\square 0.57^{* * *}$ & $\square 0.50^{* * *}$ & $\square 0.52^{* * *}$ & $\square 0.53^{* * *}$ \\
\hline & 10 & $\square 0.43^{* * *}$ & $\square 0.51^{* * *}$ & $\square 0.51^{* * *}$ & $\square 0.41^{* * *}$ & $\square 0.46^{* * *}$ \\
\hline & 11 & $\square 0.47^{* * * *}$ & $\square 0.55^{* * *}$ & $\square 0.49^{* * * *}$ & $\square 0.41^{* * *}$ & $\square 0.48^{* * * *}$ \\
\hline & 12 & $\square 0.56^{* * * *}$ & $\square 0.54^{* * * *}$ & $\square 0.55^{* * *}$ & $\square 0.60^{* * *}$ & $\square 0.56^{* * * *}$ \\
\hline & 13 & $\square 0.49^{* * * *}$ & $\square 0.50^{* * * *}$ & $\square 0.53^{* * * *}$ & $\square 0.52^{* * *}$ & $\square 0.51^{* * *}$ \\
\hline & 14 & $\square 0.54^{* * *}$ & $\square 0.50^{* * *}$ & $\square 0.53^{* * *}$ & $\square 0.51^{* * * *}$ & $\square 0.52^{* * *}$ \\
\hline & 15 & $\square 0.36^{* * *}$ & $\square 0.47^{* * * *}$ & $\square 0.41^{* * *}$ & $\square 0.29^{* *}$ & $\square 0.38^{* * * *}$ \\
\hline & 17 & $\square 0.30^{\times}$ & $\times 0.49^{*}$ & $\square 0.44^{*}$ & $\square 0.26^{\times}$ & $\square 0.37^{\times}$ \\
\hline & 18 & $\bigcirc 0.44^{* *}$ & $\square 0.49^{* * *}$ & $\square 0.48^{* * *}$ & $\bigcirc 0.37^{*}$ & $\triangle 0.44^{* * *}$ \\
\hline \multirow{7}{*}{ 西北干旱区 } & 20 & $\times 0.68^{\times}$ & $\times 1.00^{\times}$ & $\times 0.80^{\times}$ & $\triangle 0.32^{\times}$ & $\times 0.70^{\times}$ \\
\hline & 21 & $\square 0.76^{* * * *}$ & $\square 0.82^{* * *}$ & $\square 0.71^{* * *}$ & $\square 0.86^{* *}$ & $\square 0.79^{* * * *}$ \\
\hline & 22 & $\triangle 0.50^{*}$ & $\bigcirc 0.47^{*}$ & $\bigcirc 0.40^{\times}$ & $\bigcirc 0.41^{\times}$ & $\bigcirc 0.44^{*}$ \\
\hline & 23 & $\bigcirc 0.72^{* * *}$ & $\bigcirc 0.70^{*}$ & $\bigcirc 0.56^{*}$ & $\bigcirc 0.48^{*}$ & $\bigcirc 0.62^{*}$ \\
\hline & 24 & $\square 0.42^{* *}$ & $\triangle 0.49^{* *}$ & $\bigcirc 0.33^{*}$ & $\times-0.18^{\times}$ & $\bigcirc 0.27^{*}$ \\
\hline & 26 & $\square 0.61^{* * * *}$ & $\square 0.60^{* * * *}$ & $\square 0.46^{* * *}$ & $\bigcirc 0.26^{\times}$ & $\square 0.48^{* * * *}$ \\
\hline & 27 & $\square 0.66^{* * *}$ & $\square 0.70^{* * * *}$ & $\bigcirc 0.46^{*}$ & $\bigcirc 0.39^{\times}$ & $\triangle 0.55^{* *}$ \\
\hline \multirow{4}{*}{ 青藏高寒区 } & 29 & $\square 0.66^{* * * *}$ & $\square 0.53^{* * * *}$ & $\square 0.60^{* * * *}$ & $\square 0.78^{* * * *}$ & $\square 0.64^{* * * *}$ \\
\hline & 30 & $\triangle 0.92^{* * * *}$ & $\triangle 0.70^{* * * *}$ & $\triangle 0.82^{* *}$ & $\times 0.96^{*}$ & $\triangle 0.85^{* *}$ \\
\hline & 31 & $\square 0.63^{* * * *}$ & $\square 0.59^{* * * *}$ & $\square 0.54^{* * * *}$ & $\square 0.54^{* * *}$ & $\square 0.57^{* * *}$ \\
\hline & 32 & $\square 0.49^{* *}$ & $\triangle 0.51^{* *}$ & $\triangle 0.37^{* *}$ & $\triangle 0.40^{\circ}$ & $\triangle 0.44^{* *}$ \\
\hline
\end{tabular}

响时误差反而会增大, 使用气温直减率时需要 慎重。

\subsection{3 气温直减率的季节和类型差异}

\section{(1) 季节差异}

由表 3-5 可知, 中国气温直减率呈现出明显的 季节差异, 一般情况下夏季气温直减率高于冬季气 温直减率。而在个别区域, 如区域29(藏东川西区) 30 (藏南山地), 由于冬季无冷空气人侵, 而雨季又在 夏季, 导致冬季气温直减率高于夏季气温直减率。

从图 3 可以看出: (1)对于平均气温, 除东部季风 区的区域2(东北东部)、6(晋冀山地区)、12(四川盆 地)、13(贵州高原)、14(云南高原)气温直减率季节 差异小于 $0.10^{\circ} \mathrm{C} / 100 \mathrm{~m}$, 区域 9 (秦岭大巴山区) 等 于 $0.10^{\circ} \mathrm{C} / 100 \mathrm{~m}$ 外, 其余区域季节差异均大于 $0.10^{\circ} \mathrm{C} / 100 \mathrm{~m}$; (2)对于平均最低气温, 除东部季风 区的区域 2(东北东部)、4(山东辽宁半岛)、6(晋冀 山地)、9(秦岭大巴山区)、12(四川盆地)、13(贵州 高原)、14(云南高原)和青藏高寒区的区域 31(芫塘 高原青南山地) 的气温直减率季节差异小于 $0.10^{\circ} \mathrm{C} / 100 \mathrm{~m}$, 区域 8 (长江中下游平原)和区域 22(鄂 尔多斯高原)为 $0.10^{\circ} \mathrm{C} / 100 \mathrm{~m}$ 外,其他区域的季节差 异均大于 $0.10^{\circ} \mathrm{C} / 100 \mathrm{~m}$; (3)对于平均最高气温, 除青 藏高寒区的区域 29(藏东川西区) 和区域 30(藏南山 地)的气温直减率季节差异小于 $0.10^{\circ} \mathrm{C} / 100 \mathrm{~m}$, 区域 12 (四川盆地) 等于 $0.10^{\circ} \mathrm{C} / 100 \mathrm{~m}$ 外, 其他区域的季 节差异均大于 $0.10^{\circ} \mathrm{C} / 100 \mathrm{~m}$ 。

气温直减率季节差异小于 $0.10^{\circ} \mathrm{C} / 100 \mathrm{~m}$ 的区域 多集中在区域 12(四川盆地)、13(贵州高原)、14(云南 
表 5 区划尺度的平均最高气温直减率/ $\left({ }^{\circ} \mathrm{C} / \mathbf{1 0 0} \mathrm{m}\right)$

Tab.5 Lapse rates of mean maximum air temperature at the regional scale $/\left({ }^{\circ} \mathrm{C} / 100 \mathrm{~m}\right)$

\begin{tabular}{|c|c|c|c|c|c|c|}
\hline 大区 & 区域ID & 春 & 夏 & 秋 & 冬 & 年 \\
\hline \multirow{17}{*}{ 东部季风区 } & 1 & $\triangle 0.62^{* *}$ & $\bigcirc 0.68^{* *}$ & $\square 0.55^{* * *}$ & $x-0.05^{\times}$ & $\triangle 0.45^{*}$ \\
\hline & 2 & $\square 0.45^{* * *}$ & $\square 0.40^{* * * *}$ & $\square 0.45^{* * *}$ & $\square 0.29^{* *}$ & $\square 0.40^{* * *}$ \\
\hline & 3 & $\square 0.68^{* * *}$ & $\square 0.66^{* * *}$ & $\square 0.44^{* * *}$ & $\square 0.07^{\times}$ & $\square 0.46^{* *}$ \\
\hline & 4 & $\square 0.71^{* * *}$ & $\square 0.72^{* * *}$ & $\square 0.68^{* * *}$ & $\square 0.57^{* * *}$ & $\square 0.67^{* * *}$ \\
\hline & 5 & $\square 0.34^{\times}$ & $\square 0.17^{\times}$ & $\square 0.69^{* * *}$ & $\square 1.03^{* * *}$ & $\square 0.56^{* *}$ \\
\hline & 6 & $\square 0.52^{* * *}$ & $\square 0.54^{* * *}$ & $\square 0.45^{* * *}$ & $\square 0.42^{* * *}$ & $\square 0.48^{* * *}$ \\
\hline & 7 & $\square 0.65^{* * *}$ & $\square 0.70^{* * * *}$ & $\square 0.58^{* * *}$ & $\square 0.42^{* * *}$ & $\square 0.59^{* * *}$ \\
\hline & 8 & $\square 0.46^{* * *}$ & $\square 0.61^{* * *}$ & $\square 0.54^{* * *}$ & $\square 0.37^{* * *}$ & $\square 0.50^{* * *}$ \\
\hline & 9 & $\square 0.46^{* * *}$ & $\square 0.45^{* * *}$ & $\square 0.31^{* * *}$ & $\square 0.24^{* * *}$ & $\square 0.36^{* * *}$ \\
\hline & 10 & $\square 0.53^{* * *}$ & $\square 0.70^{* * * *}$ & $\square 0.65^{* * *}$ & $\square 0.44^{* * *}$ & $\square 0.58^{* * *}$ \\
\hline & 11 & $\square 0.55^{* * * *}$ & $\square 0.70^{* * * *}$ & $\square 0.59^{* * *}$ & $\square 0.41^{* * *}$ & $\square 0.56^{* * *}$ \\
\hline & 12 & $\square 0.55^{* * *}$ & $\square 0.61^{* * *}$ & $\square 0.51^{* * *}$ & $\square 0.50^{* * * *}$ & $\square 0.54^{* * *}$ \\
\hline & 13 & $\square 0.46^{* * *}$ & $\square 0.62^{* * * *}$ & $\square 0.55^{* * *}$ & $\square 0.45^{* * *}$ & $\square 0.52^{* * *}$ \\
\hline & 14 & $\square 0.58^{* * * *}$ & $\square 0.52^{* * * *}$ & $\square 0.46^{* * *}$ & $\square 0.44^{* * *}$ & $\square 0.50^{* * * *}$ \\
\hline & 15 & $\triangle 0.02^{\times}$ & $\square 0.47^{* * *}$ & $\square 0.41^{* * *}$ & $\square-0.05^{\times}$ & $\triangle 0.22^{*}$ \\
\hline & 17 & $\triangle-0.23^{\times}$ & $\times 0.02^{\times}$ & $\times 0.10^{\times}$ & $\square-0.27^{\times}$ & $\triangle-0.10^{\times}$ \\
\hline & 18 & $\triangle 0.35^{*}$ & $\square 0.49^{* * * *}$ & $\square 0.55^{* *}$ & $\triangle 0.36^{\times}$ & $\triangle 0.44^{*}$ \\
\hline \multirow{7}{*}{ 西北干旱区 } & 20 & $\triangle 0.62^{*}$ & $\times 0.92^{*}$ & $\triangle 0.54^{*}$ & $\triangle 0.17^{\times}$ & $\triangle 0.57^{*}$ \\
\hline & 21 & $\square 0.87^{* * *}$ & $\square 0.74^{* * * *}$ & $\square 0.76^{* * *}$ & $\square 0.96^{* * *}$ & $\square 0.83^{* * *}$ \\
\hline & 22 & $\square 0.77^{* * * *}$ & $\square 0.64^{* * * *}$ & $\square 0.58^{* * *}$ & $\square 0.41^{* * *}$ & $\square 0.60^{* * *}$ \\
\hline & 23 & $\square 0.79^{* * * *}$ & $\square 0.85^{* * * *}$ & $\square 0.63^{* * *}$ & $\square 0.17^{* *}$ & $\square 0.61^{* * *}$ \\
\hline & 24 & $\square 0.61^{* * * *}$ & $\square 0.74^{* * *}$ & $\square 0.47^{* * *}$ & $\times-0.28^{\times}$ & $\triangle 0.39^{* *}$ \\
\hline & 26 & $\square 0.79^{* * *}$ & $\square 0.81^{* * *}$ & $\square 0.67^{* * *}$ & $\bigcirc 0.26^{*}$ & $\square 0.63^{* * *}$ \\
\hline & 27 & $\square 0.70^{* * * *}$ & $\square 0.82^{* * * *}$ & $\square 0.53^{* * *}$ & $\square 0.19^{* * *}$ & $\square 0.56^{* * *}$ \\
\hline \multirow{4}{*}{ 青藏高寒区 } & 29 & $\square 0.68^{* * * *}$ & $\square 0.61^{* * *}$ & $\square 0.60^{* * *}$ & $\square 0.62^{* * *}$ & $\square 0.63^{* * *}$ \\
\hline & 30 & $\times 0.83^{*}$ & $\times 0.74^{*}$ & $\bigcirc 0.78^{*}$ & $\bigcirc 0.76^{* *}$ & $\bigcirc 0.78^{*}$ \\
\hline & 31 & $\square 0.62^{* * * *}$ & $\square 0.69^{* * * *}$ & $\square 0.54^{* * *}$ & $\square 0.36^{* * * *}$ & $\square 0.55^{* * *}$ \\
\hline & 32 & $\square 0.63^{* * * *}$ & $\square 0.57^{* * *}$ & $\square 0.51^{* * *}$ & $\square 0.33^{* * * *}$ & $\square 0.51^{* * *}$ \\
\hline
\end{tabular}
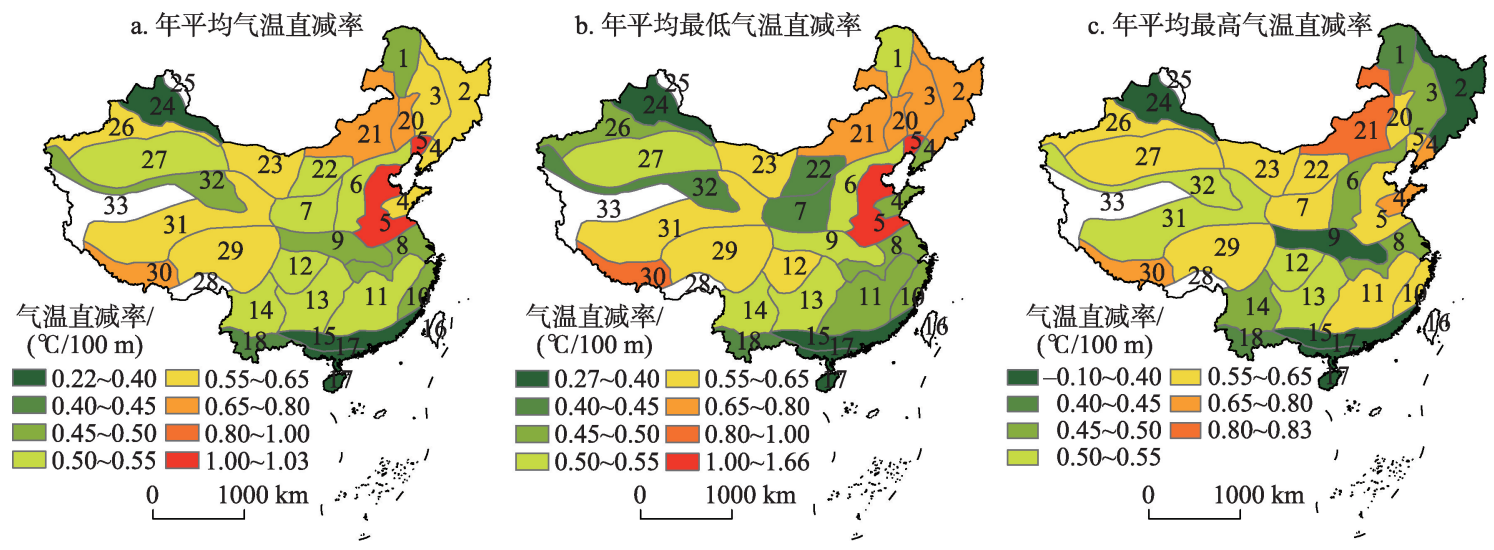

图 2 综合自然区划尺度的气温直减率空间分布图 ${ }^{\mathbb{1}}$

Fig.2 Spatial distribution of lapse rates of air temperature at the regional scale

(1)图中各分区多边形中的标注为区域ID,下同。 

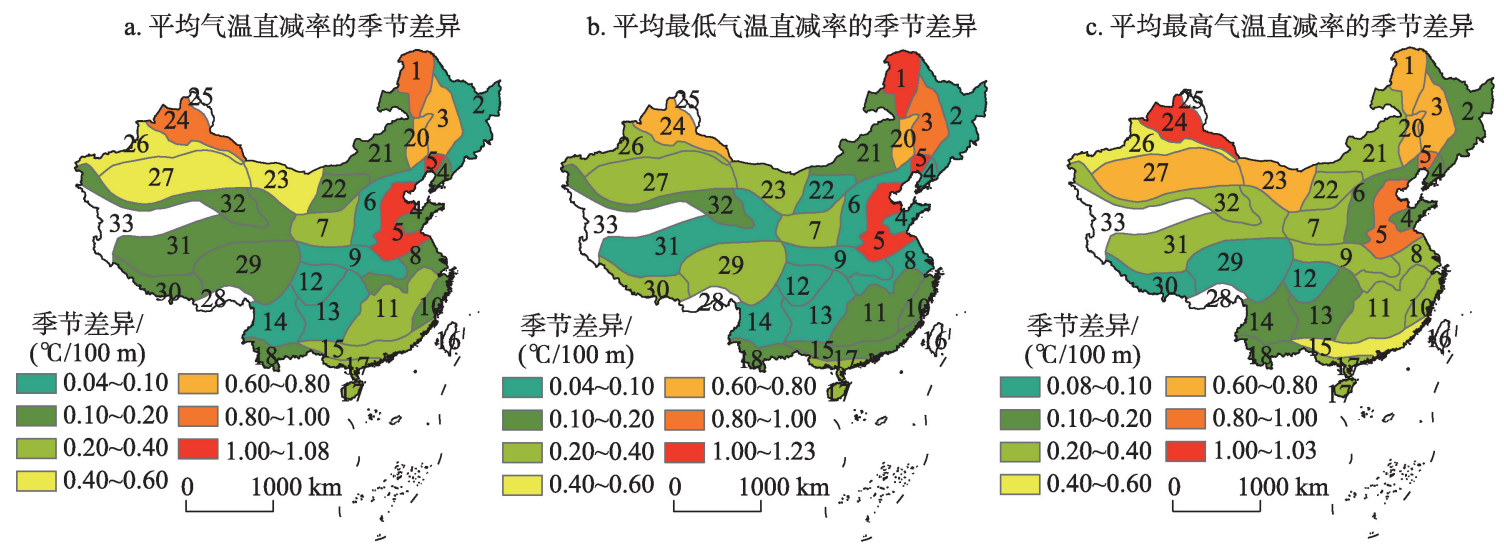

图 3 区划尺度上不同类型气温直减率的季节差异

Fig.3 Seasonal differences of the three types of air temperature lapse rates at the regional scale

高原)。四川盆地气温直减率季节差异较小与该处 周围山脉的屏蔽有关,使得冬季冷空气作用减弱; 而云贵高原边缘山脉有效阻挡东亚冷空气,也使得 该处气温直减率的季节差异较小。

\section{(2) 类型差异}

对比表 3、表 4 和表 5 可知, 在春季、夏季和秋 季, 半数 ${ }^{2}$ (春季 14 个、秋季 14 个)或过半数区域(夏 季 17 个)的 $l r_{\max }>l r_{\min }$; 而在冬季, 多数区域(20个)的 $l r_{\max }<l r_{\min }$ 。春季、夏季和秋季的 $l r_{\max }$ 最大, $l r_{\min \mathrm{T}}$ 最 小, 这是由于白天地面充当热源, 提高海拔较低处 气温(平均最高气温), 而夜间地面则充当冷源, 此外 夜间冷空气下沉也会使低海拔处气温(平均最低气 温)降低; 而在冬季, 白天地面充当热源使低海拔处 气温(平均最高气温)提高的作用不明显, 从而导致 $l r_{\text {minT }}$ 最大, $l r_{\text {max }}$ 最小, $l r_{\text {meanT }}$ 则一般处于 $l r_{\text {minT }}$ 和 $l r_{\text {maxT }}$ 之间。

各个区域内不同季节气温直减率的类型差异 (精确到小数点后两位)如图 4所示, 从图中可以发 现不同类型的气温直减率存在较大差异。(1)春季, 东部季风区和西北干旱区有近半数区域(7个、3个) 气温直减率类型差异超过 $0.10^{\circ} \mathrm{C} / 100 \mathrm{~m}$, 此外区域 10 (浙闽沿海山地)和区域 21(内蒙古高原)的类型差 异为 $0.10^{\circ} \mathrm{C} / 100 \mathrm{~m}$, 而青藏高寒区多数区域 $(3$ 个)的 气温直减率类型差异低于 $0.10^{\circ} \mathrm{C} / 100 \mathrm{~m}$ 。(2)夏季, 东部季风区和西北干旱区过半数区域(11个、6个) 气温直减率的类型差异大于 $0.10^{\circ} \mathrm{C} / 100 \mathrm{~m}$, 而青藏 高寒区全部区域(4个)的气温直减率类型差异小于 或等于 $0.10^{\circ} \mathrm{C} / 100 \mathrm{~m}$ 。(3)秋季, 东部季风区和西北 干旱区过半数区域 $(9$ 个、 4 个)气温直减率的气温直
减率类型差异大于 $0.10^{\circ} \mathrm{C} / 100 \mathrm{~m}$, 此外区域 11 (长江 南岸丘陵)的类型差异为 $0.10^{\circ} \mathrm{C} / 100 \mathrm{~m}$, 而青藏高寒 区多数区域 $(3$ 个)的气温直减率类型差异低于 $0.10^{\circ} \mathrm{C} / 100 \mathrm{~m}$ 。(4)冬季, 东部季风区、西北干旱区和 青藏高寒区过半数区域 $(9$ 个、 4 个、3 个)气温直减 率的类型差异大于 $0.10^{\circ} \mathrm{C} / 100 \mathrm{~m}$, 此外区域 12 (四 川盆地) 和区域 21(内蒙古高原) 的类型差异为 $0.10^{\circ} \mathrm{C} / 100 \mathrm{~m}$ 。(5)从年均情况来看, 东部季风区和 西北干旱区过半数区域 $(9$ 个、 4 个)的气温直减率类 型差异超过 $0.10^{\circ} \mathrm{C} / 100 \mathrm{~m}$, 此外区域 1 (大兴安岭)的 类型差异为 $0.10^{\circ} \mathrm{C} / 100 \mathrm{~m}$, 青藏高寒区所有区域的 气温直减率类型差异均低于 $0.10^{\circ} \mathrm{C} / 100 \mathrm{~m}$ 。

\section{5 结论和讨论}

本文利用国家气象站点数据, 分别在国家尺度 和综合自然区划尺度上计算了 $l r_{\text {minT }} l r_{\text {meanT }} 、 l r_{\text {maxT }}$, 进 一步研究发现: (1)在国家尺度上, 3 种气温直减率均 小于 $0.65^{\circ} \mathrm{C} / 100 \mathrm{~m} ; l r_{\text {minT }} 、 l r_{\text {mean }}$ 和 $l r_{\max }$ 的季节差异分 别为 $0.05 、 0.13$ 和 $0.24^{\circ} \mathrm{C} / 100 \mathrm{~m}$, 且具有夏季最大、冬 季最小的季节规律; 春、夏、秋、冬季气温直减率的类 型差异分别为 $0.12 、 0.05 、 0.11$ 和 $0.26^{\circ} \mathrm{C} / 100 \mathrm{~m}$, 且均 有 $l r_{\text {minT }}>l r_{\text {mean }}>l r_{\text {maxt }}$ 的规律。(2)在综合自然区划尺度 上, 气温直减率大多低于 $0.65^{\circ} \mathrm{C} / 100 \mathrm{~m}$; 气温直减率 存在明显的地域差异, 从年均情况来看, $l r_{\text {min }} 、 l r_{\text {mean }}$ 和 $l r_{\max }$ 的地域取值范围依次为 $0.27 \sim 1.66^{\circ} \mathrm{C} / 100 \mathrm{~m}$ 、 $0.22 \sim 1.03^{\circ} \mathrm{C} / 100 \mathrm{~m}$ 和 $-0.10 \sim 0.83^{\circ} \mathrm{C} / 100 \mathrm{~m}$; 气温直减 率季节差异大多超过 $0.10^{\circ} \mathrm{C} / 100 \mathrm{~m}$; 一般情况下, 夏 季气温直减率大于冬季气温直减率; 气温直减率类

(2)文中半数、过半数和近半数的统计以利用本文方法能够计算得到气温直减率数值的区域数量为基准。 


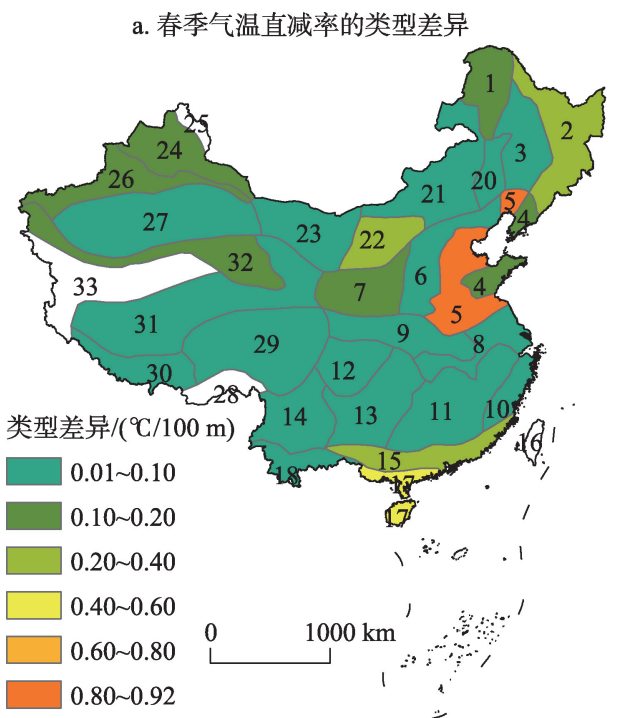

c. 秋季气温直减率的类型差异

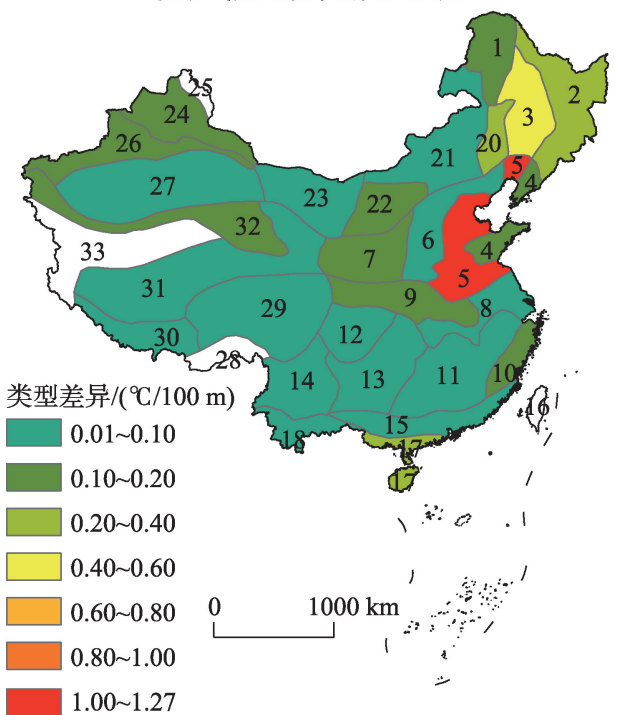

b. 夏季气温直减率的类型差异

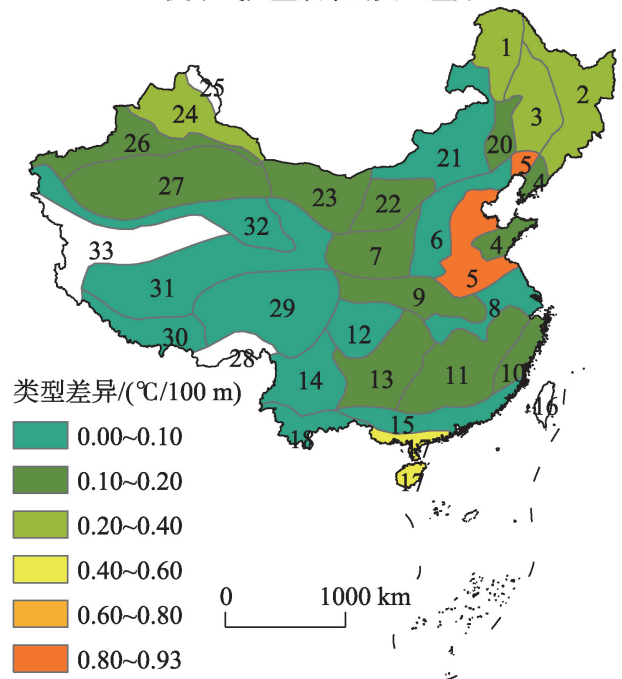

d. 冬季气温直减率的类型差异

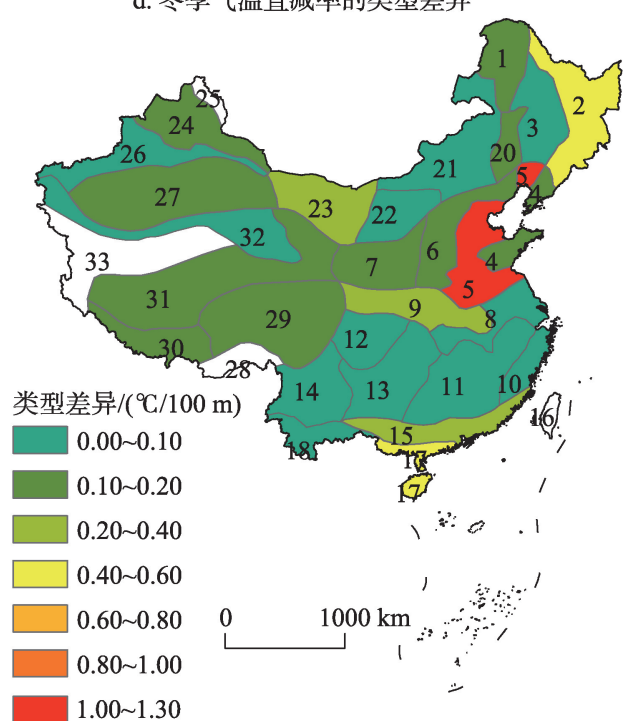

图 4 区划尺度上气温直减率的类型差异

Fig.4 Differences of the three types of air temperature lapse rates at the regional scale

型差异半数超过或等于 $0.10^{\circ} \mathrm{C} / 100 \mathrm{~m}$ 。在春、夏、秋 季, 半数左右的区域 $l r_{\max T}$ 高于 $l r_{\min }$; 在冬季, 多数区 域的 $l r_{\text {minT }}$ 高于 $l r_{\text {maxT }}, l r_{\text {meanT }}$ 一般处于 $l r_{\text {max }}$ 和 $l r_{\text {minT }}$ 之 间。综上, 中国气温直减率存在明显的季节、地域 和类型差异, 在进行气温插值时可考虑根据季节、 地域和气温类型使用合适的气温直减率。

基于地面气象站点的近地表气温直减率可为 气温空间插值提供一定的参考, 然而, 在西部山区 (尤其是青藏高原地区), 气象站点分布稀疏, 高程代 表性不足, 气温直减率可能会在不同高程范围内存 在较大差异(刘伟刚等, 2013), 使用气温直减率时需 格外谨慎。对于这些缺少气象站点的地区, 未来可
以考虑采用遥感反演方法计算气温直减率(王艳霞 等, 2014)。此外,坡向的不同(张家诚等, 1985)以及 山体效应(赵芳等, 2012)也会造成气温直减率的差 异,可在综合自然区划基础上进一步考虑坡向及山 体效应的影响。利用线性回归技术求得的气温直 减率会面临空间尺度和区划效应,不同的自然区划 分区所得到的气温直减率数值不尽相同, 不同区划 方案对气温直减率的影响将是下一步将要开展的 工作。此外, 中国气温直减率的研究已经积累了丰 富成果, 与已有研究结果进行深人对比分析, 探讨 气温直减率的时空变化规律将是非常有意义的 工作。 


\section{参考文献(References)}

方精云. 1992. 我国气温直减率分布规律的研究 [J]. 科学通 报, 37(9): 817-820. [Fang J Y. 1992. Studies on geographic distribution of the altitudinal lapse rate of temperature in China[J]. Chinese Science Bulletin, 37(23): 1979-1983.] 李军, 游松财, 黄敬峰. 2006. 中国 1961-2000 年月平均气温 空间插值方法与空间分布 [J]. 生态环境, 15(1): 109-114. [Li J, You S C, Huang J F. 2006. Spatial interpolation method and spatial distribution characteristics of monthly mean temperature in China during 1961-2000[J]. Ecology and Environment, 15(1): 109-114.]

刘伟刚, 张东启, 柳景峰, 等. 2013. 喜马拉雅山中段地区气 温直减率变化特征 $[\mathrm{J}]$. 干旱气象, 31(2): 240-245. [Liu W G, Zhang D Q, Liu J F, et al. 2013. A study on temperature lapse rate on the northern and southern slopes of the central Himalayas[J]. Journal of Arid Meteorology, 31(2): 240245.]

潘耀忠, 龚道溢, 邓否, 等. 2004. 基于 DEM 的中国陆地多年 平均温度插值方法 [J]. 地理学报, 59(3): 366-374. [Pan Y Z, Gong D Y, Deng L, et al. 2004. Smart distance searching-based and DEM-informed interpolation of surface air temperature in China[J]. Acta Geographica Sinica, 59(3): 366-374.]

山地气候文集编委会. 1984. 山地气候文集 [M]. 北京: 气象 出版社: 69-76. [Editorial Committee of Collected Works on Mountain Climate. 1984. Shandi qihou wenji[M]. Beijing, China: China Meteorological Press: 69-76.]

宋文娟, 熊黑钢, 穆桂金. 2009. 新疆博格达山北麓气候变化 分析 [J]. 干旱区研究, 26(5): 628-633. [Song W J, Xiong H G, Mu G J. 2009. Analysis on climatic change in northern piedmont of the Bogda Mountain, Xinjiang[J]. Arid Zone Research, 26(5): 628-633.]

王艳霞, 丁琨, 黄晓园, 等. 2014. 利用遥感瞬时温度场研究 云南山地气温直减率 [J]. 遥感学报, 18(4): 912-922. [Wang Y X, Ding K, Huang X Y, et al. 2014. Temperature lapse rates in the mountain regions of Yunnan Province based on remotely sensed instantaneous land surface temperature[J]. Journal of Remote Sensing, 18(4): 912-922.] 翁笃鸣, 孙治安. 1984. 我国山地气温直减率的初步研究 [J]. 地理研究, 3(2): 24-34. [Weng D M, Sun Z A. 1984. A preliminary study of the lapse rate of surface air temperature over mountainous regions of China[J]. Geographical Research, 3(2): 24-34.]

杨美华. 1981. 长白山的气候特征及北坡垂直气候带 $[\mathrm{J}]$. 气 象学报, 39(3): 311-320. [Yang M H. 1981. The climatic features of Changbaishan and its vertical climatic zone on the northern slop $[J]$. Acta Meteorologica Sinica, 39(3): 311-320.]
张洪亮, 倪绍祥, 邓自旺, 等. 2002. 基于 DEM 的山区气温空 间模拟方法 [J]. 山地学报, 20(3): 360-364. [Zhang H L, Ni S X, Deng Z W, et al. 2002. A method of spatial simulating of temperature based Digital Elevation Model (DEM) in mountain area[J]. Journal of Mountain Science, 20(3): 360-364.]

张家诚, 林之光. 1985. 中国气候 $[\mathrm{M}]$. 上海: 上海科学技术出 版社: 79-97. [Zhang J C, Lin Z G. 1985. Zhongguo qihou [M]. Shanghai, China: Shanghai Science and Technology Press: 79-97.]

张勇, 刘时银, 韩海东, 等. 2004. 天山南坡科其卡尔巴契冰 川消融期气候特征分析 [J]. 冰川冻土, 26(5): 545-550. [Zhang Y, Liu S Y, Han H D, et al. 2004. Characteristics of climate on the Keqicar Glacier on the south slopes of the Tianshan Mountains during Ablation period[J]. Journal of Glaciology and Geocryology, 26(5): 545-550.]

赵芳, 张百平, 庞宇, 等. 2012. 山体效应对北半球林线分布 的影响分析 [J]. 地理学报, 67(11): 1556-1564. [Zhao F, Zhang B P, Pang Y, et al. 2012. Mass elevation effect and its contribution to the altitude of timberline in the Northern Hemisphere[J]. Acta Geographica Sinica, 67(11): 15561564.]

郑成洋, 方精云. 2004. 福建黄岗山东南坡气温的垂直变化 [J]. 气象学报, 62(2): 251-255. [Zheng C Y, Fang J Y. 2004. Changes in air temperature varibles along altitudinal gradient in Mt. Huanggang, China[J]. Acta Meteorologica Sinica, 62(2): 251-255.]

中国科学院《中国自然地理》编辑委员会. 1985. 中国自然地 理总论 [M]. 北京: 科学出版社: 187-196. [Editorial Board of Physical Geography of China, CAS. 1985. Zhongguo ziran dili zonglun[M]. Beijing, China: Science Press: 187196.]

中山大学, 兰州大学, 南京大学, 等. 1978. 自然地理学 [M]. 北京: 人民教育出版社: 36-39. [Sun Yat-Sen University, Lanzhou University, Nanjing University, et al. 1978. Ziran dili xue[M]. Beijing, China: People's Education Press: 3639.]

Fang J Y, Yoda K. 1988. Climate and vegetation in China (I). Changes in the altitudinal lapse rate of temperature and distribution of sea level temperature[J]. Ecological Research, 3(1): 37-51.

Hargreaves G H, Samani Z A. 1985. Reference crop evapotranspiration from temperature $[\mathrm{J}]$. Applied Engineering in Agriculture, 1(2): 96-99.

Harlow R C, Burke E J, Scott R L, et al. 2004. Research note: Derivation of temperature lapse rates in semi-arid southeastern Arizona[J]. Hydrology and Earth System Sciences, 8(6): 1179-1185. 
Li X P, Wang L, Chen D L, et al. 2013. Near-surface air temperature lapse rates in the mainland China during 19622011[J]. Journal of Geophysical Research: Atmospheres, 118(14): 7505-7515.

Peng S S, Piao S L, Ciais P, et al. 2013. Asymmetric effects of daytime and night-time warming on Northern Hemisphere vegetation[J]. Nature, 501: 88-92.

Rolland C. 2003. Spatial and seasonal variations of air temperature lapse rates in Alpine regions[J]. Journal of Climate, 16(7): 1032-1046.

\title{
Near-surface air temperature lapse rates and seasonal and type differences in China
}

\author{
JIANG Jingchao ${ }^{1}$, LIU Junzhi ${ }^{2,3 *}$, QIN Chengzhi ${ }^{3,4}$, MIAO Yamin² ${ }^{2}$ ZHU A-Xing ${ }^{2,3}$ \\ (1. Smart City Research Center, Hangzhou Dianzi University, Hangzhou 310012, China; 2. Key Laboratory of \\ Virtual Geographic Environment, Ministry of Education, Nanjing Normal University, Nanjing 210023, China; \\ 3. Jiangsu Center for Collaborative Innovation in Geographical Information Resource Development and Application, \\ Nanjing 210023, China; 4. State Key Laboratory of Resources and Environmental Information System, Institute of \\ Geographic Sciences and Natural Resources Research, CAS, Beijing 100101, China)
}

\begin{abstract}
The lapse rate of near-surface air temperature is a critical parameter for obtaining high-precision air temperature products, especially in mountainous areas. The average lapse rate for the troposphere is $0.65^{\circ} \mathrm{C} / 100 \mathrm{~m}$, which cannot depict the seasonal and type differences in near-surface air temperature. This study used data from 839 Chinese national-level meteorological stations in 2000-2013 to calculate the lapse rates of seasonal mean air temperature $\left(l r_{\text {mean }}\right)$, seasonal mean minimum air temperature $\left(l r_{\text {minT }}\right)$, and seasonal mean maximum air temperature $\left(l r_{\max }\right)$ based on a multiple regression method at the national and regional scales, respectively. A spatial interpolation algorithm was used to validate the reliability of these lapse rates, and the seasonal and type differences were analyzed. The following results were obtained: (1) At the national scale, all the lapse rates are smaller than $0.65^{\circ} \mathrm{C} / 100 \mathrm{~m}$. The seasonal differences of $l r_{\min }$, $l r_{\text {meanT }}$, and $l r_{\max }$ are $0.05,0.13$, and $0.24^{\circ} \mathrm{C} / 100 \mathrm{~m}$, respectively. Generally, the lapse rates of the summer are greater than those of the winter. The differences among the three types of lapse rates of air temperature are $0.12,0.05,0.11$, and $0.26^{\circ} \mathrm{C} / 100 \mathrm{~m}$, respectively, in spring, summer, fall and winter. Generally, $l r_{\min }$ is the largest, while $l r_{\max }$ is the smallest. (2) At the regional scale by the comprehensive physical geographical regionalization, the lapse rates are also mostly smaller than $0.65^{\circ} \mathrm{C} / 100 \mathrm{~m}$. There are spatial differences for each type of lapse rate - the spatial ranges of annual $l r_{\text {minT }}$, $l r_{\text {meanT }}$, and $l r_{\max }$ are $0.27-1.66^{\circ} \mathrm{C} / 100 \mathrm{~m}, 0.22-1.03^{\circ} \mathrm{C} / 100 \mathrm{~m}$, and $-0.10-0.83^{\circ} \mathrm{C} / 100 \mathrm{~m}$, respectively. The seasonal differences of lapse rates are mostly greater than or equal to $0.10^{\circ} \mathrm{C} / 100 \mathrm{~m}$, and the lapse rates of the summer are mostly greater than those of the winter. The differences among the three types of lapse rates in half of the regions are greater than $0.10^{\circ} \mathrm{C} / 100 \mathrm{~m} . l r_{\text {max }}$ is larger than $l r_{\text {minT }}$ and $l r_{\text {meant }}$ for half of the regions in spring, summer, and fall, while $l r_{\text {mint }}$ is usually the largest in winter. Because of the seasonal differences, spatial differences, and differences among the three types of temperature lapse rates, temperature lapse rate should be determined for each season, region, and temperature type.
\end{abstract}

Key words: lapse rate of near-surface air temperature; comprehensive physical geographical regionalization; mean air temperature; mean minimum air temperature; mean maximum air temperature; China 